\title{
La responsabilidad internacional del Estado Colombiano en el Sistema Interamericano de Derechos Humanos $(2006-2013)^{*}$
}

\section{International responsibility of the Colombian State in the Inter- American Human Rights System}

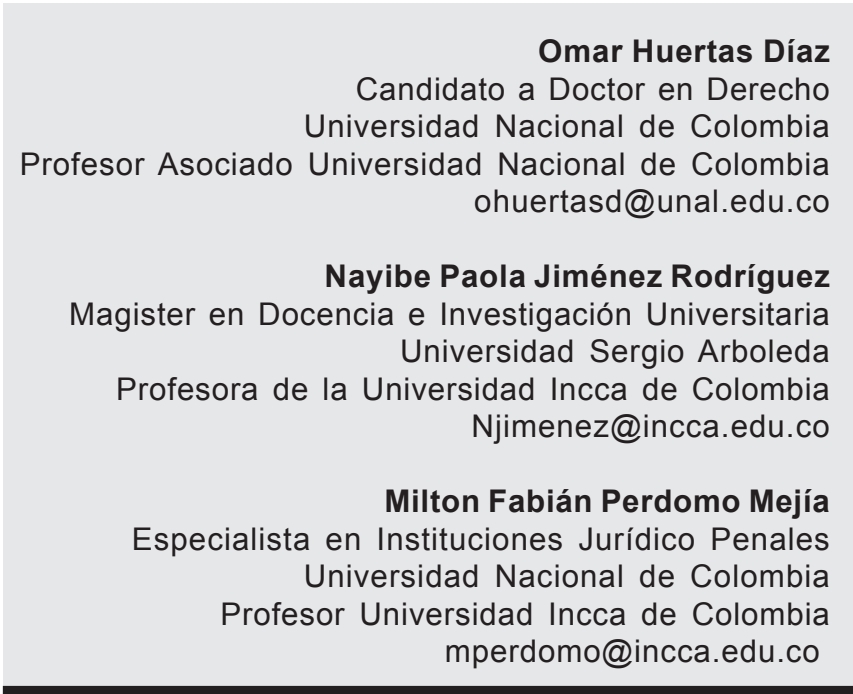

\section{RESUMEN}

El presente artículo evidencia el estudio de la responsabilidad Internacional del Estado Colombiano que ha sido desarrollada en la jurisprudencia internacional de la Corte Interamericana de Derechos Humanos, describiendo así las diferentes categorías de responsabilidad en las que puede verse inmerso Colombia, se parte entonces del incumplimiento de tratados internacionales, es decir, de obligaciones que el Estado decidió pactar con sus iguales a nivel exterior.

El desarrollo del proyecto de investigación se realiza en el marco institucional, dado el respaldo financiero que ha generado la Universidad INCCA de Colombia y su Centro de Investigación Socio Jurídicas, por medio del Grupo de Investigación «MANDELA» en Derechos Humanos, el cual presenta el Primer Informe correspondiente al proyecto de investigación titulado «LA RESPONSABILIDAD INTERNACIONAL DEL ESTADO COLOMBIANO EN EL SISTEMA INTERAMERICANO DE DERECHOS HUMANOS (2006 - 2013)».

\section{PALABRAS CLAVE}

Estado, Responsabilidad del Estado, Sistema Interamericano. 


\section{ABSTRACT}

The document shows the study by the International responsibility of the Colombian State, which has been developed in international jurisprudence of the Inter-American Court of Human Rights, and describing the different categories of responsibility which can be immersed Colombia, based on the default international treaties, ie obligations that the State decided to agree with peers at an external level.

The development of the research project is carried out in the institutional framework, given the financial backing that generated the INCCA Colombia University and its Center for Socio Legal Research through the Research Group «MANDELA» Human Rights, which presents the corresponding First Report on the research project entitled «THE COLOMBIAN INTERNATIONAL STATE RESPONSIBILITY IN AMERICAN SYSTEM OF HUMAN RIGHTS (2006 - 2013)».

\section{KEY WORDS}

State, State Responsibility, Inter-American System.

\section{INTRODUCCIÓN}

La investigación que se presenta tiene como objetivo analizar las sentencias y pronunciamientos de los órganos del Sistema Interamericano de Derechos Humanos entre los años 2006 al 2013, emitidos en contra del Estado colombiano por la violación de los derechos contenidos en la Convención Americana Sobre Derechos Humanos, con el fin de recopilar el contexto de las mismas, tanto en su contenido jurídico, como forma de recuperación de la memoria histórica que contribuya a la reconciliación en Colombia teniendo en cuenta que el Estado es titular de derechos y obligaciones internacionales, promoviendo el cumplimiento de los compromisos que se desencadenan al ser parte de los instrumentos internacionales como son las convenciones, lo que hace que «Un Estado que ha contraído válidamente obligaciones internacionales está obligado a introducir en su legislación, las modificaciones necesarias para asegurar la ejecución de los compromisos adquiridos» (Corte permanente de Justicia Internacional, 2009).

Al respecto de la responsabilidad y de los compromisos internacionales adquiridos, la Constitución de 1991, en especial los artículos 1, 2, 4, 90, 93 y 94, entre otros, ha puesto en ellos la preocupación por los derechos humanos. Así, la academia se ha preocupado por la conceptualización de estos derechos, unos trabajados a nivel nacional (derechos fundamentales), otros en plano internacional (sistema universal y regional de protección de derechos humanos). Como resultado de estos estudios, tanto en las Instituciones de Educación Superior como las organizaciones no gubernamentales (ONG), han realizado estudios científicos en materia de derechos humanos, cada uno de ellos con objetivos distintos. Basta con nombrar a las Universidades del Rosario, Externado de Colombia, Libre de Colombia, Autónoma de Colombia, Militar Nueva Granada, Javeriana, en donde los diferentes grupos de investigación se han preocupado por el cumplimiento 0 mejor, por el incumplimiento de las obligaciones derivadas de la ratificación y posterior aprobación de la Convención Americana Sobre derechos Humanos (CADH) por parte de Colombia. Esa construcción, independiente de sus puntos de abordaje, servirán a la presente investigación para ubicar en el tiempo, en el espacio y en la conceptualización, los diferentes derechos humanos que han sido violentados por los diferentes Estados parte de la $\mathrm{CADH}$, en especial, el Estado colombiano.

El conflicto armado interno vivido por más de 60 años en el Estado Colombiano es un claro ejemplo, pues ha tenido como consecuencia la violación de los derechos humanos contenidos en la Convención Americana Sobre Derechos Humanos -Pacto de San José- a través de las conductas más crueles. De ahí que se hace necesario estudiar los fallos que ha emitido la Corte interamericana de Derechos 
Humanos, así como los casos estudios por la Comisión Interamericana de Derechos Humanos, con el fin de analizar el contexto de los hechos, la evolución de la protección de los derechos consagrados en el Pacto de San José y la responsabilidad.

Ahora, cuando se viola por acción u omisión, un deber establecido por el Derecho Internacional, se origina una nueva relación jurídica, entre el sujeto a quien se le imputa el acto de responder mediante reparación, y el sujeto que posee derecho a reclamar la reparación por dicho incumplimiento, dando lugar al concepto de responsabilidad internacional que parte de la definición de «como cualquier acto o hecho que provoque una violación del derecho internacional imputable a un Estado y del cual se deriven para otro estado un daño material o uno moral» (Espinosa, 2011).

Los sujetos de Derecho internacional son los sujetos que generan las conductas responsables, por lo tanto las organizaciones internacionales pueden caer en este suceso, así como los individuos, aunque frente a estos quedan excluidos de la responsabilidad internacional por lo que no son responsables ellos mismos, sino el Estado cuya nacionalidad tienen, por lo que dado el caso, no pueden hacer responsable a un Estado distinto que no sea el suyo. Sin embargo para el presente recaerá el estudio en la responsabilidad originada por los Estados.

Del concepto indicado se puede inferir los siguientes elementos:

1. Acto o un hecho que provoca una violación del Derecho internacional: se refiere a la posibilidad de que aunque no se desprenda de la voluntad la realización del hecho que ocasione la responsabilidad internacional, es evidente que eso no es suficiente para evitar el daño ocasionado y por lo tanto, se tiene el deber de repararlo o dicho de otro modo, regresar las cosas al momento en que se encontraban antes del suceso.

2. Hecho imputable al Estado: es decir que la causa de la responsabilidad, no es sólo un acto de voluntad sino también, puede ser un hecho pero que pueda imputarse al Estado, y

3. Ocasionar un daño bien sea material o moral.

De esta forma, Cuando un sujeto de Derecho Internacional viola una obligación internacional, sin importar la fuente de dicha obligación, se genera alli una responsabilidad internacional. Las violaciones tradicionales pueden ser la falta de cumplimiento de un tratado, la conculcación de privilegios e inmunidades diplomáticas, la violación territorial de un Estado o bien, la expresión de palabras que ofendan la moral o el honor del Estado o una omisión de conducta por parte de un Estado (Espinosa, 2011).

La investigación presente obedece a una investigación de paradigma cualitativo, empleando un método descriptivo. Es importante destacar como lo hace Mejía (2004) que la importancia que tiene el desarrollo de la investigación de tipo cualitativo es que esta investigación permite conocer fenómenos complejos de la realidad social a partir de lo cual se pretende construir conceptos muy abstractos, como los sentimientos, procesos de pensamientos y emociones, peo para el caso en concreto es que permite conocer la naturaleza de un grupo que forma un todo muy específico. Estos grupos constituyen unidades sociales muy integradas que pueden ser profesionales, étnicos, raciales, familiares, gremiales o institucionales (educativos) o también pueden ser grupos que comparten formas de vida y situaciones que los hacen semejantes como los sujetos que intervienen en procesos de enseñanza-aprendizaje.

También se dice que los métodos cualitativos son humanistas, pues no se pierde de vista el aspecto humano de la vida social, llegando a conocer lo experimental y personal del ser humano, sus sentimientos, éxitos y fracasos etc.; frente a la investigación cualitativa no se trabajó el concepto de confiabilidad o reproducibilidad de la investigación, sino de validez de esta, claro que no puede afirmarse que no importe la precisión de los datos, ya que esta clase de investigación se desarrolla de forma sistematizada con procedimientos rigurosos, aunque no necesariamente estandarizados, pero sujetos a los 
errores humanos; todos los aspectos y fenómenos de la vida social son dignos de estudio; y por último se trata de un arte (Taylor y Bogdan, 1987).

\section{DESARROLLO DEL TEMA}

Para la construcción del marco referencial, estado del arte y marco teórico, se realizó una selección sobre el material escrito que reposa en diferentes Bibliotecas públicas, privadas y personales, en donde se ha procurado encontrar la bibliografía que refiera sobre los temas de investigación, así como la búsqueda en diferentes bases de datos contentivas de material electrónico de la materia. De la misma manera, se han decantado los principales pronunciamientos que ha tenido la Corte Interamericana de Derechos Humanos, en especial en los casos en donde se ha encontrado la responsabilidad internacional de Colombia por violaciones a los derechos de la Convención Americana Sobre Derechos Humanos, siendo esta jurisprudencia y ese marco legal internacional la base de la investigación.

\subsection{Sistema Interamericano de Derechos Humanos}

El Sistema Interamericano de Derechos Humanos, se fundamenta en la integración de todos los estados del continente americano, para ello, y en búsqueda de ese objetivo y cimiento, se crearon y adoptaron tres instrumentos internacionales que recogieran los intereses generales de la región: La Declaración Americana de Derechos Humanos, La Carta de la Organización de Estados Americanos (OEA) y la Convención Americana Sobre Derechos Humanos.

Si bien es cierto, todos los anteriores instrumentos internacionales son importantes en la conclusión de la integración planeada, el presente informe se centra en la Convención Americana Sobre Derechos Humanos, al considerar que es el tratado con mayor fuerza vinculante en la protección de los Derechos Humanos en el territorio colombiano, además de que es el instrumento que, al ser ratificado, otorga competencia contenciosa a la Corte Interamericana de
Derechos Humanos y la Comisión Interamericana de Derechos Humanos.

El marco teórico se encuentra fundamentado en el desarrollo jurisprudencial de la Corte Interamericana de Derechos Humanos como máxima guarda y ente jurisdiccional frente a las violaciones de Derechos Humanos reconocidos en la Convención Americana de Derechos Humanos. Así el marco teórico versa sobre la obligación que adquirió Colombia al ratificar la convención Americana de derechos Humanos, de respetar los derechos, lo cual integra unas obligaciones estatales generales, garantía, respeto, e igualdad y no discriminación, y finalmente las consecuencias jurídicas del no cumplimiento de dichos deberes.

\section{RESULTADOS}

\subsection{Obligación de respetar los derechos según la Convención americana de derechos Humanos}

Según la convención Americana de Derechos Humanos, parte I, capítulo 1, artículo 1. los Estados parte de la convención se comprometen a respetar los derechos y libertades reconocidos en ella y a garantizar su libre y pleno ejercicio a toda persona que esté sujeta a su jurisdicción, sin discriminación alguna por motivos de raza, color, sexo, idioma, religión opiniones políticas o de cualquier otra índole, origen nacional o social, posición económica, nacimiento o cualquier condición social, lo cual permite determinar que se pone a cargo de los estados parte el respeto, garantía, y menoscabo a los derechos humanos, atribuidos como lo establece el derecho Internacional por las acciones y omisiones imputables a cualquier autoridad pública, comprometiendo así su responsabilidad.

Se puede establecer como primera obligación, en los términos de la convención Americana de Derechos Humanos, respetar los derechos y libertades, imponiendo así límites a la función pública, sustentados en la dignidad humana como principio y valor superior al poder del Estado.

También se desprende como obligación garantizar el libre pleno ejercicio de los derechos reconocidos 
en la Convención, lo cual implica una organización del aparato gubernamental, y de las estructuras de los poderes públicos, de manera tal que exista la certeza de prevenir, investigar, y sancionar toda violación de los derechos reconocidos en la nombrada convención, así como su restablecimiento y la reparación de los daños acaecidos. Debe resaltarse que el libre y pleno ejercicio de los derechos humanos no se agota con la mera existencia de normatividad, sino que debe coexistir con la eficacia de los mecanismos de acceso a dicha libertad y seguridad del ejercicio de los derechos humanos.

\subsection{Responsabilidad internacional por violación a Derechos Humanos sustentada en la Convención Americana de Derechos Humanos}

Se declara la responsabilidad o condena de un Estado, cuando la Corte Interamericana de Derechos Humanos, considera que dicho Estado a través de sus actos ha incumplido con las obligaciones ratificadas en la convención Americana, causando perjuicios a los Derechos Humanos de las víctimas.

Este Tribunal ha establecido a lo largo de su jurisprudencia que la responsabilidad internacional de los Estados, en el marco de la Convención Americana, surge en el momento de la violación de las obligaciones generales, de carácter erga omnes, de respetar y hacer respetar-garantizar- las normas de protección y de asegurar la efectividad de los derechos allí consagrados en toda circunstancia y respecto de toda persona, recogidas en los artículos 1.1 y 2 de dicho tratado (Caso Masacre de Pueblo Bello). De estas obligaciones generales derivan deberes especiales, determinables en función de las particulares necesidades de protección del sujeto de derecho, ya sea por su condición personal o por la situación específica en que se encuentre. En este sentido, el artículo 1.1 es fundamental para determinar si una violación de los derechos humanos reconocidos por la Convención puede ser atribuida a un Estado Parte en todo su alcance. En efecto, dicho artículo impone a los Estados Partes los deberes fundamentales de respeto y garantía de los derechos, de tal modo que todo menoscabo a los derechos humanos reconocidos en la Conven- ción que pueda ser atribuido, según las reglas del Derecho Internacional, a la acción u omisión de cualquier autoridad pública, constituye un hecho imputable al Estado que compromete su responsabilidad internacional en los términos previstos por la misma Convención y según el Derecho Internacional general. Es un principio de Derecho Internacional que el Estado responde por los actos y omisiones de sus agentes realizados al amparo de su carácter oficial, aun si actúan fuera de los límites de su competencia (Caso Masacre de Pueblo Bello).

La Corte ha establecido que la responsabilidad internacional de los Estados, en el marco de la Convención Americana, surge en el momento de la violación de las obligaciones generales recogidas en los artículos 1.1 y 2 de dicho tratado (Caso de la Masacre de Pueblo Bello; Caso de la Masacre de Mapiripán y Condición Jurídica y Derechos de los Migrantes Indocumentados.). De estas obligaciones generales derivan deberes especiales, determinables en función de las particulares necesidades de protección del sujeto de derecho, ya sea por su condición personal o por la situación específica en que se encuentre (Caso de la Masacre de Pueblo Bello), como extrema pobreza o marginación y niñez.

Es claro para la Corte que un Estado no puede ser responsable por cualquier situación de riesgo al derecho a la vida. Teniendo en cuenta las dificultades que implica la planificación y adopción de políticas públicas y las elecciones de carácter operativo que deben ser tomadas en función de prioridades y recursos, las obligaciones positivas del Estado deben interpretarse de forma que no se imponga a las autoridades una carga imposible o desproporcionada (Caso de la Masacre de Pueblo Bello). Para que surja esta obligación positiva, debe establecerse que al momento de los hechos las autoridades sabían o debían saber de la existencia de una situación de riesgo real e inmediato para la vida de un individuo o grupo de individuos determinados, y no tomaron las medidas necesarias dentro del ámbito de sus atribuciones que, juzgadas razonablemente, podían esperarse para prevenir o evitar ese riesgo (Caso de la Masacre de Pueblo Bello). 
La responsabilidad internacional del Estado se fun$\mathrm{da}$ en "actos $\mathrm{u}$ omisiones de cualquier poder $\mathrm{u}$ órgano de este, independientemente de su jerarquía, que violen la Convención Americana»(Caso del Penal Miguel Castro Castro). Para establecer que se ha producido una violación de los derechos consagrados en la Convención no se requiere determinar, como ocurre en el derecho penal interno, la culpabilidad de sus autores o su intencionalidad y tampoco es preciso identificar individualmente a los agentes a los cuales se atribuyen los hechos violatorios (Caso La Cantuta; Caso Masacre de Pueblo Bello; y Caso de la Masacre de Mapiripán). Es suficiente la demostración de que ha habido apoyo o tolerancia del poder público en la infracción de los derechos reconocidos en la Convención (Caso 19 Comerciantes) omisiones que hayan permitido la perpetración de esas violaciones o que exista una obligación del Estado que haya sido incumplida por este (Caso Masacre de Pueblo Bello; Caso de la Masacre de Mapiripán; y Caso 19 Comerciantes).

Para establecer la responsabilidad internacional del Estado con motivo de la violación a los derechos humanos consagrados en los artículos 8.1 y 25 de la Convención Americana, un aspecto sustancial de la controversia ante la Corte no es si en el ámbito interno se emitieron sentencias o se llegó a acuerdos conciliatorios por responsabilidad administrativa 0 civil de un órgano estatal, en relación con las violaciones cometidas en perjuicio de las víctimas de violaciones a los derechos humanos o sus familiares, sino si los procesos internos permitieron que se garantizara un pleno acceso a la justicia conforme a los estándares previstos en la Convención Americana (Caso de la Masacre de Mapiripán).

En los casos de la Masacre de Mapiripán, la Masacre de Pueblo Bello y las Masacres de Ituango, los tres contra Colombia, la Corte estimó que la reparación integral de una violación a un derecho protegido por la Convención no puede ser reducida al pago de compensación a los familiares de la víctima. El Tribunal señaló que las indemnizaciones dispuestas en los procesos contencioso administrativos podían ser consideradas al momento de fijar las reparaciones pertinentes, «a condición de que lo resuelto en esos procesos haya hecho tránsito a cosa juzgada y que sea razonable en las circunstancias del caso (Caso de la Masacre de Mapiripán).

La Corte ha señalado que en casos de violaciones de derechos humanos el deber de reparar es propio del Estado, por lo que si bien las víctimas o sus familiares deben tener amplias oportunidades también en la búsqueda de una justa compensación en el derecho interno, este deber no puede descansar exclusivamente en su iniciativa procesal o en la aportación privada de elementos probatorios. De tal manera, en los términos de la obligación de reparación integral que surge como consecuencia de una violación de la Convención, el proceso contencioso administrativo no constituye per se un recurso efectivo y adecuado para reparar en forma integral esa violación (Caso de las Masacres de Ituango, y Caso de la Masacre de Pueblo Bello).

Pues una reparación integral y adecuada, en el marco de la Convención, exige medidas de rehabilitación, satisfacción, y garantías de no repetición. La Corte ha indicado que recursos como la acción de reparación directa o la acción de nulidad y restablecimiento del derecho tiene unos alcances mínimos y unas condiciones de acceso no apropiadas para los fines de reparación que la Convención Americana establece. La Corte indicó que es la producción de un daño antijurídico y no la responsabilidad del Estado ante el incumplimiento de estándares y obligaciones en materia de derechos humanos lo que decreta en su sentencia una autoridad judicial en lo contencioso administrativo (Caso de las Masacres de Ituango).

Ahora, debe decirse que la Corte carece de competencia para declarar que un Estado es internacionalmente responsable por la violación de tratados internacionales que no le atribuyen dicha competencia, se puede observar que ciertos actos u omisiones que violan los derechos humanos de acuerdo con los tratados que le compete aplicar infringen también otros instrumentos internacionales de protección de la persona humana, como los Convenios de Ginebra de 1949 y, en particular, el artículo 3 común (Caso Bámaca Velásquez). 
Hay efectivamente equivalencia entre el contenido del artículo 3 común de los Convenios de Ginebra de 1949 y el de las disposiciones de la Convención Americana y de otros instrumentos internacionales acerca de los derechos humanos inderogables (tales como el derecho a la vida y el derecho a no ser sometido a torturas ni a tratos crueles, inhumanos 0 degradantes). Esta Corte ya ha señalado, en el Caso Las Palmeras (2000), que las disposiciones relevantes de los Convenios de Ginebra pueden ser tomados en cuenta como elementos de interpretación de la propia Convención Americana (Caso las palmeras).

\subsection{Responsabilidad internacional a un Esta- do por acción u omisión de sus órganos o funcionarios}

Según Huertas (2005) y siguiendo la convención Americana es ilícita toda forma de ejercicio del poder público que viole los derechos humanos, así que cuando un órgano, un funcionario del estado 0 una institución pública lesione algún derecho reconocido por la convención, se está en presencia de una posible responsabilidad internacional del estado al no guardar observancia con lo regulado por la Convención Americana. De esta forma, no importa si los funcionarios actúan fuera de los límites de su competencia, contravienen las disposiciones del Derecho Interno, o si por el contrario no realizan las actos de su injerencia, se está en presencia de una posible responsabilidad internacional del estado, ya que es principio del derecho Internacional que el estado responde por los actos de sus agentes, ejecutados en sustento de su carácter oficial.

\subsection{Responsabilidad internacional por actos au- torizados, por actos de particulares y por actos individuales}

Es imputable al estado toda violación a los derechos reconocidos por la Convención Americana de derechos Humanos, realizada por actos de los poderes públicos, o por la responsabilidad criminal de individuos, ya que es deber de los estados parte, prevenir, investigar, y sancionar las violaciones de los Derechos Humanos.
Así que un hecho ilícito que pueda resultar no directamente imputable al estado, puede acarrear la responsabilidad internacional del mismo por falta de debida diligencia para prevenir la violación 0 para tratarla.

La Corte concluye que el cumplimiento por parte de agentes o funcionarios del Estado de una ley manifiestamente violatoria de la convención produce responsabilidad internacional del Estado. En caso de que el acto de cumplimiento constituya un crimen internacional, genera también la responsabilidad internacional de los agentes o funcionarios que lo ejecutaron (Huertas et al. 2005).

\section{CONCLUSIONES}

De acuerdo con lo establecido por los tratados internacionales de los que el Estado hace parte, y respetando el principio de derecho internacional denominado pacta sunt servanda, cada miembro parte de los convenios internacionales es responsable por su aplicación e implementación en el derecho interno de cada Estado. De ahí que el incumplimiento de estas responsabilidades generen como consecuencia la responsabilidad internacional del Estado miembro que acate lo por este pactado.

Teniendo en cuenta el contexto de cooperación y compromiso internacional de los sujetos de Derecho internacional como lo son los Estados, debe resaltarse la responsabilidad internacional de estos, que se origina como consecuencia de las vulneraciones o incumplimiento de las obligaciones que en dicho contexto se han pactado, responsabilidad que se puede reflejar en la jurisprudencia de la Corte Interamericana de Derechos Humanos, desarrollada a partir de la violación a Derechos Humanos consagrados en la Convención Americana de Derechos Humanos.

Dado los conceptos y avances logrados por la jurisprudencia de la Corte Interamericana al respecto, se ha determinado que la responsabilidad internacional puede derivarse según sea el caso por: a. acción u omisión de sus órganos o funcionarios y b. por 
actos autorizados, por actos de particulares, y por actos individuales.

Ahora, dichas formas de responsabilidad se aplican al incumplimiento de las obligaciones pactadas en la convención Americana de derechos humanos por parte del Estado Colombiano, como se puede evidenciar en los casos masacre de Ituango, Mapiripan, Bámaca Velásquez, 19 comerciantes, Las palmeras, y Pueblo bello.

\section{REFERENCIAS BIBLIOGRÁFICAS}

- Espinosa, J (2011). Derecho internacional público. México: Facultad de Estudios Superiores Acatlán.

- Huertas, $O$ et al. (2005). Convención Americana de Derechos Humanos. Colombia: Universidad Autónoma de Colombia. Bogotá: Editorial Ibáñez.

- Huertas, O (2006). Colombia ante la Corte Interamericana de Derechos Humanos Recuperación de la Memoria Histórica 1995-2006. Bogotá: Editorial Ibáñez.

- Huertas, $O$ (2007). El Derecho a la Vida en la Perspectiva del Derecho Internacional de los Derechos Humanos. Bogotá: Editorial Ibáñez.

- Huertas, $O$ (2007). La Libertad Personal en el Derecho Internacional de los Derechos Humanos. Bogotá: Editorial Ibáñez.

- Huertas, O (2008). El Principio de Igualdad y No Discriminación a la luz del Derecho Internacional de los Derechos Humanos. Bogotá: Editorial Ibáñez.
- Mejía, J. (2004). Sobre la investigación cualitativa. Nuevos conceptos y campos de desarrollo. Lima: Investigaciones sociales.

- Taylor, S, Bogdan, R (1987). Introducción a los métodos cualitativos de investigación. España: Paidós.

- El Pacto de San José de Costa Rica Convención Americana sobre Derechos Humanos. (2007). Bogotá: Editorial Ibáñez.

- Corte Interamericana de derechos Humanos. Caso Masacre de Pueblo Bello, supra nota 12, párr. 111; Caso de la «Masacre de Mapiripán», supra nota 12, párr. 111; y Condición Jurídica y Derechos de los Migrantes Indocumentados. Opinión Consultiva OC-18/03 de 17 de septiembre de 2003. Serie A No. 18, párr. 140.

- Corte Interamericana de derechos Humanos. Caso del Penal Miguel Castro Castro, supra nota 8, párr. 31.

- Corte Interamericana de derechos Humanos. Caso La Cantuta, supra nota 8, párr. 156.

- Corte Interamericana de derechos Humanos. Caso 19 Comerciantes. Sentencia de 5 de julio de 2004. Serie C No. 109, párr. 141.

- Corte Interamericana de derechos Humanos. Caso Cantos. Sentencia de 28 de noviembre de 2002. Serie C No. 97, párr. 28.

- Corte Interamericana de derechos Humanos. Caso de las Masacres de Ituango, supra nota 15, párr. 340.

- Corte Permanente de Justicia Internacional (2009). Serie $B$, núm. 10. 